\title{
Fiber Optic Device
}

National Cancer Institute

\section{Source}

National Cancer Institute. Fiber Optic Device. NCI Thesaurus. Code C50358.

A device made with thin fibers of glass or plastic as a conduit for the transmission of light. 